\title{
Optional published refereeing
}

\author{
Kumar, Kaplesh; Gordon, R A
}

Published in:

Physics Today

Link to article, DOI:

$10.1063 / 1.2995480$

Publication date:

1979

Document Version

Publisher's PDF, also known as Version of record

Link back to DTU Orbit

Citation (APA):

Kumar, K., \& Gordon, R. A. (1979). Optional published refereeing. Physics Today, 32(4), 13-13.

https://doi.org/10.1063/1.2995480

\section{General rights}

Copyright and moral rights for the publications made accessible in the public portal are retained by the authors and/or other copyright owners and it is a condition of accessing publications that users recognise and abide by the legal requirements associated with these rights.

- Users may download and print one copy of any publication from the public portal for the purpose of private study or research.

- You may not further distribute the material or use it for any profit-making activity or commercial gain

- You may freely distribute the URL identifying the publication in the public portal

If you believe that this document breaches copyright please contact us providing details, and we will remove access to the work immediately and investigate your claim 


\section{Natural laws for humans}

I was intrigued by the letter dealing with analogies between the physical and social sciences by Dan McLachlan (January, page 13) - both for what it affirmed, and for what it implicitly denied.

McLachlan makes the positive suggestion that perhaps there are natural laws that govern human relations, that is, perhaps there is an area of objective reality in interpersonal relationships, and all is not subjective and relative after all. $\mathrm{He}$ suggests that we search for these laws using the same kind of scientific methodology that has proved so successful in dealing with the physical universe. I heartily second this whole approach, and would simply like to add that perhaps we already know more than we sometimes think we do that our problem is not lack of knowledge, but wrong choices concerning the knowledge we already have.

When McLachlan states, "We haven't broken a law of nature yet," the statement is somewhat misleading. Actually, if we attempt to break a law of nature, we suffer the consequences of its inflexible reality. We cannot break the law of gravity by jumping off a tall building, but we can certainly injure ourselves by trying to. Jumping off a tall building is the equivalent of "sin" in the purely physical context; the consequent injury is the equivalent of "judgment."

Given this perspective, McLachlan may be a bit too hasty in dismissing laws "passed down by our religious leaders" as another kind of law. Religious leaders, being human beings, are certainly capable of handing down all kinds of incorrect information about natural laws that govern human relationships; they do this when they pass off human opinion for objective reality. If, on the other hand, the Creator of the universe were pleased to inform us of the essentials of those natural laws governing human relations, we would know a good deal of supreme importance before we could get around to establishing (if ever we could) these kinds of laws scientifically.

The Ten Commandments and the Sermon on the Mount are examples of such codifications of natural laws governing human beings, which are in agreement, so far as I am aware, with anything that has been established by authentic scientific investigation. Be- cause these laws deal with human choice and relationships, their outworking is more complex than those laws that deal only with the physical universe. Does anyone debate that we ought to love our neighbor as ourselves? Why do we so often fail to do so?

A person restrains himself from jumping off a tall building because he wants to survive. Why do people not restrain themselves from oppressing other human beings, treating another person as an object, turning their backs on those in suffering to maintain their own self-centered satisfactions and thus survive as whole human beings? The answers to those questions take you right back to religion.

$1 / 23 / 79$

RICHARD H. BUBE Stanford University Stanford, California

\section{Optional published refereeing}

R. A. Gordon's letter on optional published refereeing was quite interesting (October, page 81 ). While I agree with most of his recommendations, it seems some changes are needed to make his approach more "just."

Entrusting authors with responsibility for publication of a controversial manuscript (with the reviewer's comments printed alongside) is a good idea. As Gordon has stated, authors would truly be .. running a considerable risk to their professional reputations. .." by publishing low-grade material, especially so when it is accompanied by the reviewer's "thorough, objective. . . criticism." But, what if the review reports are not thorough and objective? (This, too, is not uncommon in the world of science.) In such a case, it serves no purpose to retain the anonymity of the reviewer. If anything, the reviewers should clearly be prepared to put their professional standing on the line if that is to be expected from the authors. As a fallout of such a system, both the quality of publications that are submitted and the quality of refereeing that is done will most likely improve substantially.

It is also not clear why Gordon does not want to give the authors a chance for rebuttal. A meaningful rebuttal not only

\section{THE \\ BNC PULSER FAMILY}

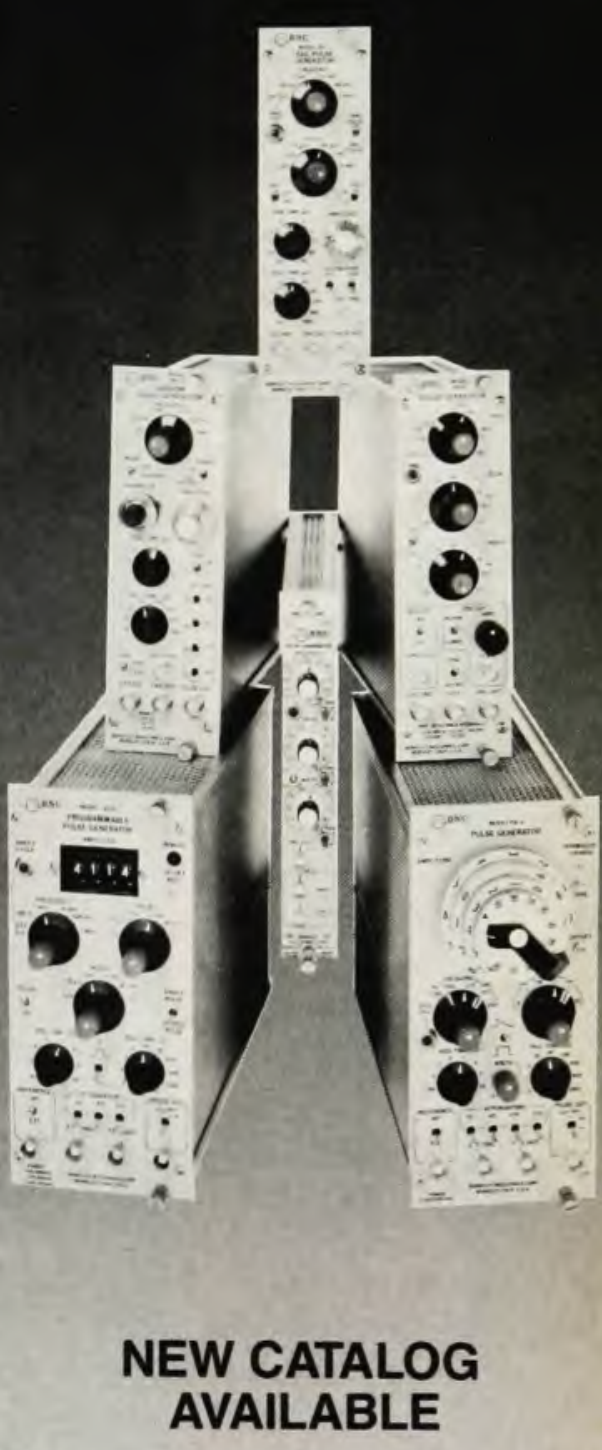

Berkeley Nucleonics has a pulse generator for almost every job. Our pulsers cover a range from economical, general purpose models to programmable, precision ones. The pulsers are versatile and are used in many areas including design, performance testing, and calibration. Get our NEW SHORT FORM CATALOG and meet our family. Phone (415) $527-1121$ or write to:

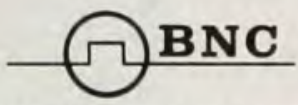

Berkeley Nucleonics Corp.
1198 Tenth St.

Berkeley, Ca. 94710

Circle No. 11 on Reader Service Card 


\section{Breakthrough in Cryogenic Pumping}

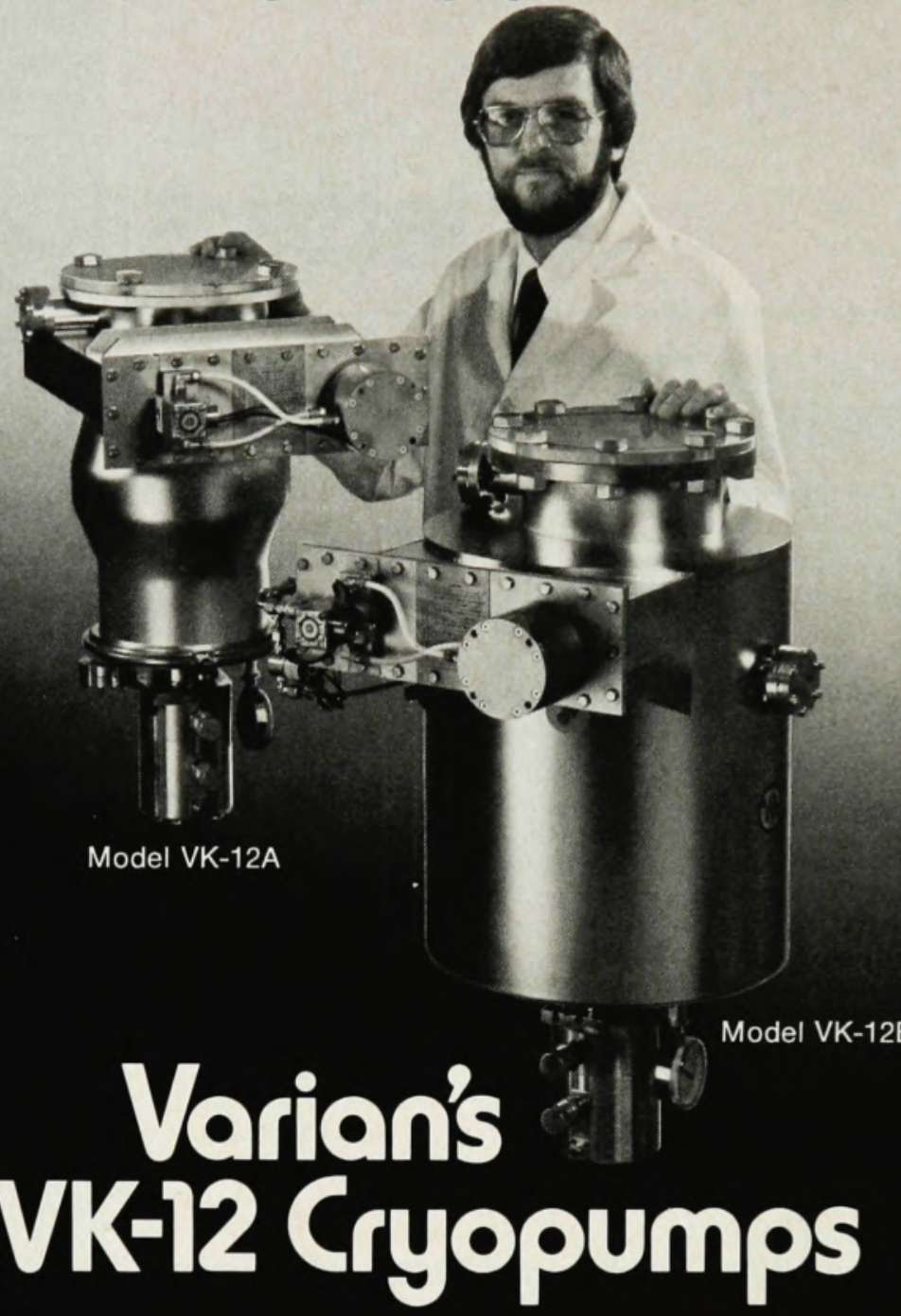

These closed-loop cryopump modules are different from all others. They have:

- High conductance through an integrated, reliable swing valve

- Superior efficiency from a proprietary cryoarray

Your choice of two models:

- VK-12A: general purpose cryopump

- VK-12B: specifically designed for sputtering and electron beam coating systems

These "clean" vacuum pumps offer many advantages. They are power efficient, low in maintenance and designed to meet the demands of ultrahigh vacuum and production environments.

Ask for complete specifications. You will find a new standard of performance. Varian, Palo Alto Vacuum Division, 611 Hansen Way, Palo Alto, CA, 94303. 415-493-4000.

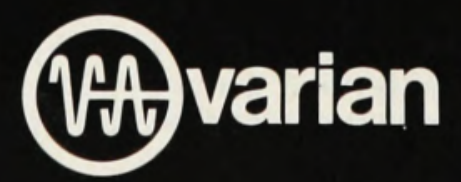




\section{letters}

addresses issues raised by the reviewer but, in so doing, also lays down an added justification for publication of the manuscript, thereby adding a new dimension to the original contribution. If however, authors were to issue a rebuttal to defend an already untenable scientific position, as indicated by a "thorough and objective" referee report, publication of the rebuttal (in addition to the manuscript) would seriously undermine their professional standing.

In conclusion, the system proposed by Gordon certainly deserves a chance, but only if the identities of the reviewers are disclosed and only if the authors are given the opportunity to defend their work publicly in writing.

KAPLESH KUMAR The Charles Stark Draper Laboratory, Inc. 11/13/78 Cambridge, Massachusetts THE AUTHOR REPLIES: The system of optional published refereeing I originally proposed has the advantage that it could be readily implemented by most journals using existing refereeing procedures. Journals would, of course, be free to adopt any of a number of different variations of optional published refereeing that might better suit their specific needs and those of their readers. Thus, journals desiring a more open an evenly balanced dialogue between referees and authors could adopt the proposal described in detail in the above letter by Kaplesh Kumar. Other journals might wish to encourage a more flexible exchange between authors and referees by letting referees themselves decide whether or not their reports should be published. (Should referees exercise this option, the manuscript could then simply be published without the referee's report). ${ }^{1}$ Still other journals might prefer to place additional emphasis on the seriousness of the published refereeing option by requiring a mandatory rethinking period of six months for both referees and authors before the author would be allowed to publish a criticized manuscript. ${ }^{2}$

In practice, the variation of optional published refereeing best suited to a given journal will, of course, depend not only on the special advantages of each variation but also on such practical considerations as the availability of referees and the amount of additional editorial or administrative work that might be required. The essential point, however, which all of the variations of optional published refereeing share in common, is that the author will always have the option and responsibility for publishing the manuscript in question (preferably with the referee's or editor's comments) whenever it became clear that the dialogue between the authors and referees was not likely to resolve an important point of disagreement. It is precisely in such cases, where the ultimate validity of a given manuscript can be determined only by the long-term attention and participation of the interested physics public, that optional published refereeing is most advantageous, since it enables the discussion to be brought into the open in a form that specifically encourages an objective evaluation of the essential points in question. It would also, as noted before, lead to improved refereeing and maunscripts in general. The desirability of such a result for authors, referees, journals and the interested physics public is sufficiently great that it can only be repeated that a system of optional published refereeing, adapted to the specific needs of individual journals, deserves at least a trial period by a number of physics journals.

\section{References}

1. B. K. Forscher, Science 150, 319 (1965).

2. C. McCutchen, New Scientist 70, (no. 998), 225 (1976).

R. A. GORDON The Technical University of Denmark $12 / 7 / 78$ Lyngby, Denmark

\section{Call for papers}

A special issue of the IEEE Transactions of Electron Devices scheduled for January 1980 will be devoted to Infrared: Materials, Devices, and Applications. The purpose of this special issue is to cover the broad state-of-art in the infrared field, which has dramatically changed under the impact of the development of new concepts for large-scale, integrated arrays. Papers are solicitied that cover infrared materials, detectors and related devices, and various systems and applications.

The paper deadline is 1 May 1979. All manuscripts or requests for more information should be directed to the guest editor:

Professor Andrew J. Steckl

Rensselaer Polytechnic Institute

Electrical and Systems Engineering Dept.

Troy, New York 12181 (518-2706313)

\section{Tokamak instabilities}

Your news story on the successful containment of high-temperature ions in the Princeton Large Torus (November, page 17) rang a bell when I read the statement that, at the high temperature achieved in the Princeton tokamak, the collisionless trapped-particle instabilities did not show up. I recall Kadomtsev and Pogutse ${ }^{1}$ having predicted that instabilities driven by trapped particles in a tokamak cannot be completely eliminated. But I also recall that Richard Briggs and I, in a cursory analysis ${ }^{2,3}$ had concluded that the high dielectric background formed by the untrapped particles could reduce the danger continued on page 66

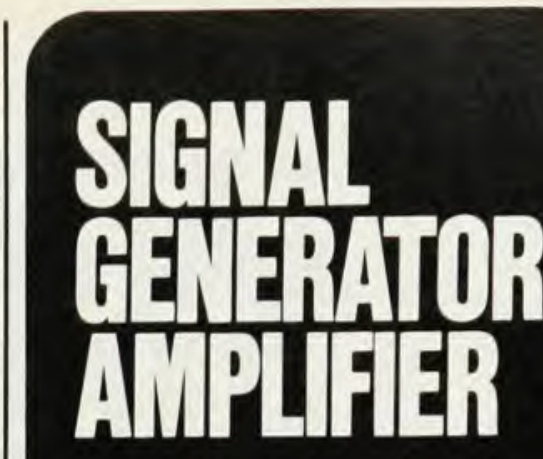

Our Model $603 \mathrm{~L}$ is the ultimate in RF signal generator amplifiers. Just plug this low cost unit into any signal or sweep generator in its 0.8 to 1000 $\mathrm{MHz}$ range and this completely solid state unit will provide you with the maximum in power flexibility.

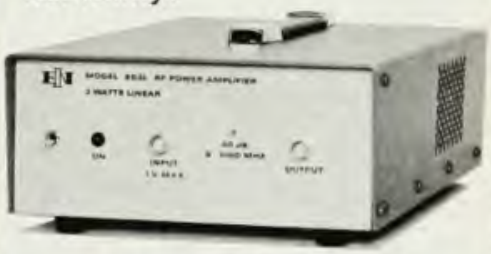

With a flat frequency response and 3 watts of linear Class A output (up to 5 watts saturated), the $603 \mathrm{~L}$ will provide constant forward power, making it ideal for driving reactive or resistive loads.

Priced at $\$ 1895^{\star}$, the versatility and usefulness of this outstanding power amplifier can best be demonstrated in your own applications.

For detailed specifications or a demonstration, please contact:

\section{ENI}

3000 Winton Road South

Rochester, New York 14623

Call: $716-473-6900$ or

Telex: 97-8283 ENI ROC

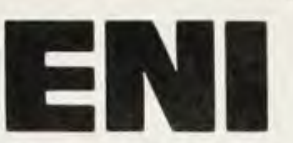

The World's Leader in Power Amplifiers 